\title{
From Mild to Wild: Reimagining Friendships and Romance in the Time of Pandemic Using Design Fiction
}

\author{
Sumita Sharma \\ INTERACT Research Unit, University \\ of Oulu, Oulu, Finland \\ sharma.sumita@oulu.fi \\ Grace Eden \\ Department of Human-Centered \\ Design, Indraprastha Institute of \\ Information Technology, Delhi \\ (IIITD), India. \\ Ritwik Kar \\ Indraprastha Institute of Information \\ Technology, Delhi (IIITD), India
}

\author{
Netta Iivari \\ INTERACT Research Unit, University \\ of Oulu, Oulu, Finland \\ iivari.netta@oulu.fi
}

\author{
Alipta Ballav \\ Independent Researcher, Bangalore, \\ India
}

\section{Deepak Ranjan Padhi \\ IDC School of Design, Indian Institute of Technology Bombay, Mumbai, Maharashtra, India}

\author{
Marianne Kinnula \\ INTERACT Research Unit, University \\ of Oulu, Oulu, Finland \\ kinnula.marianne@oulu.fi \\ Rocío Fatás \\ Human Centered Design, \\ Srishti-Manipal Institute of Art, \\ Design and Technology, Bangalore, \\ Karnataka, India \\ Vahid Sadeghie \\ Department of Ergonomics and \\ Industrial Safety, School of Public \\ Health and Safety, Shahid Beheshti \\ University of Medical Science, Tehran, \\ Islamic Republic of Iran

\section{Rucha Tulaskar \\ Tampere University, Tampere, Finland}

Pratiti Sarkar

IDC School of Design, Indian Institute of Technology Bombay, Mumbai, Maharashtra, India

\author{
Riya Sinha \\ Indraprastha Institute of Information \\ Technology, Delhi (IIITD), India \\ Nikita Valluri \\ Independent Researcher, Bangalore,
}

\begin{abstract}
With the forced reboot of our lives due to the COVID-19 pandemic, our interpersonal relationships are nowhere yet everywhere. However, opportunities for initiating or maintaining friendships and romance in the physical world have dwindled. Within the context of India where multiple realities exist, the question arises - what is the future of these relationships? In this paper, we present the outcomes of a workshop looking at the future of relationships using design fiction. Participants worked in small teams to create scenarios that critically consider the future of love, friendships, and romance within the Indian context. Through the lenses of criticality, empowerment, and value creation, we examine the design scenarios and the design process including criticality of the designs, empowering experiences of the participants, and the perceived value gained from participating in such a workshop. Our findings indicate the potential of design fiction to allow participants to step
\end{abstract}

\section{(c) $($ ) $\ominus$}

This work is licensed under a Creative Commons Attribution-NoDerivs International 4.0 License.

DIS '21, fune 28-fuly 02, 2021, Virtual Event, USA

(C) 2021 Copyright held by the owner/author(s).

ACM ISBN 978-1-4503-8476-6/21/06.

https://doi.org/10.1145/3461778.3462110 out of their comfort zone into a critical stance in discussing love and intimacy. Based upon our findings, we discuss implications for design research, practice, and education.

\section{CCS CONCEPTS}

- Human-centered computing $\rightarrow$ Human computer interaction (HCI); Empirical studies in HCI; • Social and professional topics $\rightarrow$ User characteristics; Cultural characteristics.

\section{KEYWORDS}

Design Fiction, Friendships and Romance, Empowerment and Provocation, COVID-19 Pandemic, India, Global South

\section{ACM Reference Format:}

Sumita Sharma, Netta Iivari, Marianne Kinnula, Grace Eden, Alipta Ballav, Rocío Fatás, Ritwik Kar, Deepak Ranjan Padhi, Vahid Sadeghie, Pratiti Sarkar, Riya Sinha, Rucha Tulaskar, and Nikita Valluri. 2021. From Mild to Wild: Reimagining Friendships and Romance in the Time of Pandemic Using Design Fiction. In Designing Interactive Systems Conference 2021 (DIS '21), fune 28-fuly 02, 2021, Virtual Event, USA. ACM, New York, NY, USA, 14 pages. https://doi.org/10.1145/3461778.3462110

\section{INTRODUCTION}

The COVID-19 pandemic has transformed how we work and socialize. No longer do we meet in person to discuss projects and 
plans in offices and at universities as social distancing has pulled us from our workplaces. It also disconnected us from our personal relationships, where meeting physically with friends and partners has become a health and safety risk. To keep the virus at bay, we have shifted some of the most important aspects of our lives online [15]. Self-isolation has become 'the new normal', bringing its own challenges when interacting with the people close to us through our computers and mobile devices. As the pandemic, unfortunately, continues to rampage throughout the world almost a year later, it is imperative to think about how to design for an empowering future that builds, maintains, and augments human relationships, through activities like online dating, connecting friends, or intimate online encounters. There is an intangible value in empowering individuals not only in their reimagined alternative future but in the here and now, where it can be comforting to consider scenarios that take place when the pandemic is behind us even if it has irrevocably changed our lives. Not everyone in the Human Computer Interaction (HCI) community has the tools to reimagine a future that challenges the current status quo, that is empowering albeit provocative, or to question, critically reflect upon, and deal with these new changes. Design fiction is one such tool.

Design fiction has entered the method repertoire of $\mathrm{HCI}$ research some time ago and is postulated as a valuable tool for envisioning futures; for collaborating and communicating with stakeholders; and for addressing critical concerns (see e.g. [55]). It has been linked with the design research tradition, particularly with Speculative Design [27, 64] and Critical Design [27] as well as with Participatory Design (PD), User-Centered Design (UCD), and Scenario writing $[30,50,55]$. As these various backgrounds indicate, design fiction is an ambiguous concept with multiple meanings and usages attached to it [55]. We are particularly inspired by the empowering potential of design fiction, which has been addressed so far in a very limited manner. Inspired by and extending this stream of design fiction research, we explore design fiction as a tool for empowerment, in collaboration with HCI professionals and academics including experts and non-experts in design research, in the context of reimagining a more empowering future in the middle of the COVID-19 crisis. Our focus is on human (and non-human e.g. AIs) relationships, including friendships and romance, considering the challenges and opportunities that have been exposed through experiences with the ongoing pandemic (see e.g. [14]). With this in mind, we conducted an online workshop employing the design fiction process to explore the future of technology for friendships and romance.

In this paper, we present the process and outcomes of our online workshop, which was part of the ACM SIGHCI Mumbai Chapter meet in June 2020, where participants worked in small teams to create future scenarios for technologies for friendships and romance. We focus on two main research questions. First, we ask within the socio-cultural context of India, where the combination of technology and romance is not well studied, what is the future of love and romance in a post pandemic world? Our goal was to enable participants to critically explore the topic, producing provocative, from mild to wild, alternative future scenarios and technologies, against the backdrop of their experiences of the pandemic. Our second research question enquires whether design fiction helped us go from a place of comfort to a place of being critical (and out of our zone of comfort) in the discussions of this important topic. We chose a workshop format in order to reach out to a wider audience, to spark inspiration, and encourage participants to consider the pandemic situation differently. We gathered data during and after the online workshop taking two perspectives in our analysis: the design outcomes and the design process. These were analysed through three lenses: criticality of design [4, 5], empowering design [39, 45] and the value co-creation in design $[36,66]$. With this work we add to the small but growing body of research on technology for friendships and romance in India (see e.g. [2, 16, 57]). We also add to ongoing research on design fiction with non-designer communities such as university students $[73,74]$ and primary school students to engage young people critically in a changing world 'such that they become empowered to act positively and knowledgeably' [53].

The paper is organized as follows. First, we present the related work in this domain which includes an overview of studies exploring the use of technology for romance in India, and a brief introduction of design fiction in $\mathrm{HCI}$ as a tool for everyone, and in times of uncertainty. Next, we present the theoretical lenses applied in this work, followed by the research design and the findings from the data collected. Lastly, we discuss the implications of our work and conclude the paper.

\section{RELATED RESEARCH}

Design fiction represents a future-oriented, speculative design tradition that has been labeled as design avant-garde [40], within which one aims at imagining and exploring speculative futures and alternative presents, at provoking and bending or violating cultural norms and rules, at envisioning alternatives, and at deconstructing and questioning existing notions, practices and technology (see e.g. $[1,9,23,52])$. However, much of the work in design fiction does not seem to adhere to particular emancipatory or empowering aims; challenging the status quo; nor a strong commitment to the empowerment of the oppressed or marginalized. Some examples can be found that particularly focus on controversies or ethical issues around design and technology (see e.g. [3, 7]), while some are strongly inspired by the Scandinavian participatory design tradition aligning with its democratization agenda [10, 54, 70]. However, there is a lack of research on specific topic of the empowering potential of design fiction. In this section, we first discuss studies on online friendships and romance in India, to situate our work in the context, then present the versatility of design fiction as a tool employed with diverse groups of users, from children to university students to regular citizens, and lastly discuss the potential of design fiction to empower us during this time of crisis.

\subsection{Exploring Online Friendships and Romance in India}

There are limited studies exploring online opportunities for finding love and romance in India. Studies exploring technology use in the slums of Bangalore and Mumbai revealed the perseverance and persistence of young adults using Facebook, which they access via internet cafes, to find love outside their community, in online spaces that level the playing field $[2,57]$. For them, online platforms like Yahoo chat and Facebook are a safe way to gain attention and interact 
freely. In the urban slums of Kolkata, a study on virtual approaches to heterosexual mate-seeking indicated that young Muslim women were interested in online friendships [16], exploring through chat rooms and matrimonial sites that are accessed from internet cafes and/or mobile phones. Such online engagement was regarded as a symbol of class and modernity. Moreover, young women consider it a safer option, one that reduces physical risks, and eliminates the social taboo of physical contact in public [22,60].

Online dating is popular not only worldwide but also in India [41], although it shares the space with arranged marriages, which are common. Previously, getting married and falling in love were combined in a single step that came shortly after gaining employment. However, times are changing, and these steps are separated and extended. Further, there are universally shared social anxieties at play, formed from pop culture narratives, the opinions of peers, longer working hours, and subsequent feelings of loneliness [18]. There are then certain culture-specific behaviors such as Indian men and women reacting differently to online deception, Indian men being more open to the idea of finding a partner online, and Indian women who register on dating sites choose to not discuss it with friends and family for fear of being judged [41]. Unsurprisingly, online dating has become popular despite many reservations amongst people, especially during the time of the pandemic, as digital avenues supply the only means forming connections. Dating applications have experienced a surge in downloads [61]. In addition, there has been a significant rise in text and video conversations during the lockdown [17]. However, how these changes fare in the future, within the layered and complex Indian socio-cultural environment, is underexplored: Can design fiction transform places of comfort to those open to critique to discuss socially uncomfortable subjects such as love and intimacy?

\subsection{Design Fiction for All}

Since the time of its inception, the term 'Design Fiction' (see [62]) has been constantly evolving and adapting to suit the context it has been applied to, from 'diegetic prototypes' [62] to 'narratives' and 'stories' [64], and contradictorily as a 'world building' activity with a focus on interactions [20], instead of narratives, with a focus on prototypes to think about the future [31, 53]. As the definitions of Design Fiction evolve, so do its application areas, employed with audiences as young as 9 years to undergraduate university students. In the Mantle of The Expert teaching method [53] design fiction was utilized to elicit discussions on environmental issues from primary school students (aged 9-10 years). Design fiction has also been adapted for students in secondary school to empower them towards becoming 'educated citizens in a democratic society' [37] and to consider ways of overturning neoliberal educational paradigms in schools of the near future [25]. With university students, design fiction assisted in imagining a future sustainable campus [33], and in critically analysing the ethical aspects of innovative technology [75]. In the framing of design fiction as a futuring tool in participatory education, the designer plays the role of a mediator as well as a creator [13], helping develop essential abilities in futures literacy 'in the same way as, during the industrial revolution, it was necessary to read and write' (ibid).
Further, design studio students are taught, through researchdriven approaches, to consider artefacts from potential and plausible futures to exemplify the process of 'world building', thereby conducting 'research into design fiction, done through design fiction' [20,21]. In this role, the fiction designer is imagined as a force that serves to 'subvert the tropes of the technology industry' [21]. Instead of following the logic of utopian and dystopian futures, in an alternative interpretation of the futures cone that places the preferable in the vertical axis as subjective point of view. In addition, fiction is described as 'a resource for design research' [47] in participatory design, engaging participants 'with a particular use of make-believe' mediated by props, as a framework for expressing needs and concerns. In another instance, design fiction is imagined as mediating dialogue between the academic and industrial world, where the ambiguity of boundary objects 'means that participants can speculate without worrying about negative implications being drawn for the present' [12]; the same authors cite Dunne \& Raby as describing critical design as having 'at its heart the subversion of status quo through the deployment of irony and satire' (ibid). Although design fiction is seen as a tool for community building [8], to empower vulnerable communities [56, 58], to encourage breaking out of typical approaches, solutions, and mindsets $[11,24,30,72]$; participatory design fiction is understood to be still in its very beginnings [50].

Design fiction is utilized also as a tool, a component of a research methodology, often in combination with other methods, for example, to train students to analyse and address complex socio-technical problems with a systems thinking mindset [73, 74]. Design fiction and scenario analysis was used to imagine facets of the future involving precision medicines, with researchers from integrated sciences, psychology, and biotechnology working towards one solution, "as an opportunity for experts from different disciplines to also teach and learn from each other" [73]. In addition, York et al. [74] present possibilities of adapting design fiction and scenario analysis to considering potential futures of autonomous vehicles, teaching middle school students about STEM education, and public engagement strategies to encourage discussion about plausible and preferable futures across all age groups.

\subsection{Design Fiction in a Time of Uncertainty}

The reflective approaches of design fiction that challenge the status quo by questioning the present, extends well to the current situation of the pandemic [46]. As the ongoing pandemic necessitates a rapid transformation for intimate interaction, there is a need to breakout of typical thinking patterns and mindsets. Gatehouse [32] provides a speculative account of the change in hierarchies within society, as well as emerging roles and behaviors, describing current scenario of the pandemic as an inverted carnivalesque experience while depicting the need for improvised forms of social relationship going forward. Similarly, experiences of various social distancing measures and lockdowns across the world, suspend our beliefs about what is normal [32]. This presents an opportunity for us to explore how we might create new orders from such an uncertain time.

Facilitating intimacy through technology has been examined through video conferencing and co-presence, tangible objects, 
notifications, and other modalities [63, 67, 69] and the relationship between sexuality and technology, an under investigated and marginalized area of research in HCI, brings with it new possibilities, concepts, and a level of maturity to our research domain [35]. In terms of how we might enrich intimate relationships through technology; the degree to which we can communicate emotions and thoughts through a device so that it becomes an extension of ourselves will determine the degree of intimacy others can experience [29]. Even with so much research in the area of novel intimate interaction, during lockdown, the technologies available to people are currently constrained to the visual and verbal. Design fiction provides mechanisms to consider alternatives pathways to building and maintaining relationships and to reimagine what constitutes as love, intimacy, or relationships. Could this forced reboot propel us towards empowering future quests for love?

\section{THEORETICAL FRAMEWORK}

This work critically examines not only the outcomes of the workshop on friendships and romance in India in a post pandemic world, but also the process, that is, experience of the workshop; to provide a holistic account of utilizing design fiction for empowerment. Thus, we employ three theoretical lenses - first, critically to examine the future scenarios created during the workshop; second, to understand whether participants were empowered in their approach towards critically designing a future for an uncomfortable topic; and third, the perceived value gain from their participation.

Barzdell extensively discuss what characterizes criticality in design [6] citing Dunne and Raby, who argue that critical design "rejects how things are now as being the only possibility, it provides a critique of the prevailing situation through designs that embody alternative social, cultural, technical or economic values" (ibid). Dunne and Raby [26] are seen as the pioneers of critical design (labeled as design avant garde), in which criticality broadly entails scrutinizing the current situation, opening up taken for granted assumptions and/or provoking the audience [40]. The provocative, shocking, uncomfortable, disturbing, absurd, and preposterous nature of critical design is often underscored for the purpose of critically exploring alternative presents and futures, as well as for awareness raising and reflection [5, 6, 9, 40, 68]. Another element of criticality is taking action for change where criticality in design may entail proposals for change [4] and even actual action taking for the empowerment of the oppressed and combating the oppressors [40]. This leads us to our second analytical lens: empowerment.

Empowerment is a complex concept discussed within different disciplines, while it has been addressed also in connection with design outcome and process [39, 40,45]. Empowerment may be seen as a motivational construct in which it is framed to include increased self-efficacy, impact, self-determination, and meaningfulness $[39,65]$. This represents a mainstream approach to empowerment, while a critical approach can also be identified [39, 45] Empowerment may also be described as a relational construct, relating to increased power over something or someone [19, 39]. Moreover, empowerment can be seen purely as an individual issue, or it can also be approached as a collective one, with feelings of social responsibility and empowerment of a collective rather than focusing on the self alone $[39,42]$.
The lenses of criticality and empowerment enable us to scrutinize both the design process and its outcome: where we can examine whether the designs created are provocative (shocking, uncomfortable, disturbing, absurd, preposterous - for the purposes of exploring alternative presents and futures, or for awareness raising and reflection); as well as whether the design process was perceived as provocative. In addition, these lenses allow us to examine whether the designs created were empowering (in the motivational or relational sense, and concerning individuals or collectives) as well as whether the design process was perceived as empowering. These two lenses informed the planning of the workshop contents and structure and were further used as frameworks for data analysis.

Through the lens of value creation, we aim to understand how the participants benefited from the workshop and what kind of value they experienced $[43,44]$. We approach value creation as it is understood in service science [36] and service dominant logic (SDL) [66]. In SDL, the experience of the actors is in focus. It is possible to plan for their value experience but in the end, the actors themselves define whether they experience value or not. The value experienced can also be different from the planned or expected value [44, 45]. Value experience is thus subjective and highly contextualized [38]. It can be related to the process or its outcome and is dependent on the expectations of the actors $[43,44]$ and their motivations to participate [48]. Often the value is seen later, when some time has passed, through sensemaking [51, 71] and reflection [49]. Thus, value experience is also temporal [43, 44]. This lens was utilized in the data analysis phase.

\section{RESEARCH DESIGN}

The online workshop was conducted in June 2020, as a part of the ACM SIGCHI Mumbai Chapter Meet, and was preceded by an invited guest talk from an Iranian researcher on an unrelated topic. Participation was voluntary and free. A workshop format was chosen to maximize our reach and it was advertised in Indian SIGCHI social media. Participants had to pre-register and those who did were sent a consent form to sign online prior to the workshop. The focus of the workshop, on friendships and romance, was not mentioned at this stage. This was intentional; staying true to our goals (of empowerment, criticality, and provocation) we wanted to provoke the participants, get them out of their comfort zones to consider and discuss shocking, provocative, and uncomfortable future scenarios during the workshop. What participants did sign-up to was a workshop to learn and utilize future oriented methods. Immediately after the workshop, participants provided feedback anonymously through an online survey. Two-months later in August 2020, participants were asked to reflect on their workshop experience and to re-consider their team scenarios from a critical perspective. This was achieved by asking them to critically analyse their own and other teams design scenarios using Bardzell et al.'s [4] matrix for reading critical design. The workshop organizers analysed the design scenarios of all the teams using the same matrix. In total, data analyses included the participants' design scenarios, post workshop feedback, and participant reflections. 
Table 1: Team activity tasks during the workshop in June

\begin{tabular}{|c|c|}
\hline Step 1: Create a scenario & Step 2: Consider the following questions \\
\hline $\begin{array}{l}\text { Imagine and describe a scenario for friendship or romance in the } \\
\text { future; the following questions are examples of what you can } \\
\text { consider: } \\
\text { What technology is used? } \\
\text { What do people value in relationships? } \\
\text { What will our lives and love be like? } \\
\text { What would friendships mean? }\end{array}$ & $\begin{array}{l}\text { What kind of things would be acceptable / not acceptable? } \\
\text { What impact will the technology have on future users? } \\
\text { What are some unintended consequences to society or for the } \\
\text { users? }\end{array}$ \\
\hline
\end{tabular}

\subsection{Workshop Procedure}

The workshop ran for 90-minutes and was conducted via Zoom. It consisted of three parts. At first, participants were introduced to design fiction through examples and discussions, and included opportunities to think about the potential futures using a version of the futures cones [27]. Building upon this taxonomy (potential, probable, plausible, and preferable), we then asked participants to consider provocative or preposterous futures [68], motivating them to imagine scenarios that question the status quo, that make the present (or future) uncomfortable, that are provocative or preposterous, and that are empowering (for everyone). First, participants worked in teams of between 5-7 members for about 30 minutes on a potential future scenario or context, using a set of questions (see [Table 1]). A total of seven teams were formed but only six were active. They used Google documents or slides in a shared folder to ideate and discuss. Finally, each of the six teams briefly presented their scenarios to the larger group, discussing the challenges in socially distant relationships and the human desire for intimacy and touch. Several of the scenarios are presented in the findings section and the activities are described in Table 1

While the workshop started with 34 participants, the team activity participation included a total of 29 , as some had to leave due to other commitments and others dropped out due to an unreliable internet connection. The 34 workshop participants were a mix of HCI students (5 BSc, $2 \mathrm{MSc}, 8 \mathrm{PhD}$ ), researchers in academia (4), faculty or teachers (4), and industry professionals (7). Participants had varying backgrounds and levels of expertise in design, HCI, and computer science. The 29 participants who took part in team activities included 12 males and 26 females, all over the ages of 18 years, with 26 Indian and 3 Iranian nationals (one of whom dropped out of the call in the middle of the activity). The workshop moderators included 1 Finn, 1 Indian, and 1 American nationals (all females). The six groups contained a mix of male and female participants with Group1 (2F, 4M), Group 2 (1M, 4F), Group 3 (1M, 4F), Group $4(2 \mathrm{M}, 2 \mathrm{~F})$, Group 5 (2F, 3M), and Group 6 (1M, 3F). As mentioned already, the workshop was conducted within the context of India as a part of the ACM SIGCHI Mumbai Chapter meet.

\subsection{Post-workshop Online Feedback Survey and Participant Reflections}

A week after the workshop, participants were sent an online feedback survey to fill in anonymously and received 13 responses. The survey enquired about participants' motivation to attend the workshop, what they liked and disliked, if their expectations were met, if they were inspired at a personal and/or professional level, and how the workshop could be improved in the future. For each of these questions, participants answered in free-form text. Two months after the workshop, the participants were asked to write personal reflections regarding the workshop by considering the following questions:

- Did the workshop give you new thoughts on the future of technology? Do you think that is something that makes you uncomfortable or shocked can help you to get new thoughts on possible futures?

- Was your own design provocative? Preposterous? Shocking? Empowering? In what sense? Why do you think so?

- Did the topic (future of friendship and romance online) make you uncomfortable? Why?

Nine participants submitted approximately 400-500-words writeup answering these questions.

\subsection{Data Analysis Procedure}

As mentioned previously, data analysed included: a critical analysis of the alternative future scenarios created during the workshop, the anonymous online feedback after the workshop, and personal reflections of participants two months later. Specifically, data analysis was conducted at two levels using three theoretical lenses, as shown in [Figure 1].

Workshop outcomes: At the first level, we considered the workshop outcomes, each of the six future scenarios were saved in an online document, where we utilized critical and empowerment lenses in their analysis. The scenarios were analysed using Bardzell et al.'s [4] matrix of common argument types to highlight how, even in a short workshop, participants can critically and provocatively question the present and consider alternative futures for friendships and romance. The matrix serves as an 'inventory of supports' (ibid) to guide readers in deciding whether a design supports criticality in relation to a set of design norms and conventions, or not. In the matrix, rows and columns correspond to interaction design dimensions, and to dimensions of criticality, respectively. The interaction design dimensions are: the 'topic/problem' space, it's central 'purpose,' its 'functionality' in terms of performing/ letting its users perform, 'interactivity' with humans through input/output, the physical 'form/structure' of the design, and 'materiality' of the 
RESEARCH DATA

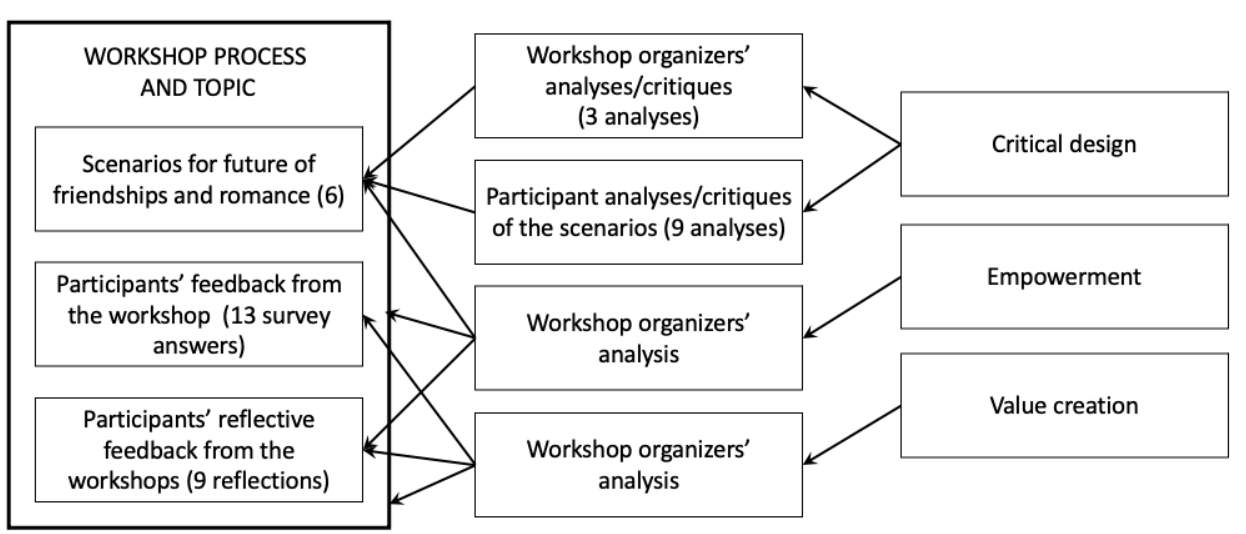

Figure 1: Data analysis process

design. The dimensions of criticality are: a new point of view contributing in 'changing perspectives' for the user, 'proposing for change' by making a plausible suggestion, 'enhancing appreciation' for design in context of a socio-cultural issue and on its level of user and/or design's 'reflectiveness.' Bardzell et al. [4] neither suggest evaluating against all 24 possible types of arguments nor do they fix a set number of quantifiable dimensions for a design to be classified as 'critical'. Instead, they first advise readers to contemplate if the design feels critical, and if so, then take the assistance of at least one out of the 24 arguments to bring analytical clarity to that intuition.

The analysis was conducted individually by nine of the participants (although all of them were invited), and by three of the organizers, where two of them met online to analyse collaboratively. Next, the participants' analyses of the scenarios were thematically grouped together and summarized. Participants' analysis is contrasted with the organizers' analysis in this paper, not to judge the scenarios or analyses, but to showcase how, as mentioned by Bardzell et al. [4], criticality, which is almost always subjective, was experienced by participants and organizers. Further, we highlight the diversity of thought and perspectives, as well as subjectivity of criticality, enabling both organizers and participants to take something personal and unique out of the experience.

Workshop process: At the second level, we considered the workshop process and its overall experience through the data collected from feedback survey and critical reflections. This data was analysed using both empowerment and value-creation lenses in the analysis of the participant responses. The feedback survey was thematically analysed to understand the challenges and opportunities for the workshop process, and consequently its outcomes, in addition to the value experienced through workshop participation and beyond. The reflections were similarly analysed and to remain true to their form, are presented as excerpts with a light summary. The participants who emailed their reflections were invited to coauthor and contribute to this paper. We further looked at the shortterm or immediate experiences (with the feedback survey) and a longer-term reflection spread across a longer term of two months (reflections) through a value creation lens. We asked ourselves, as workshop organizers - what were the immediate benefits reported by the participants and how were they transformed over the course of two months, when experiences can sometimes feel exaggerated (better) or attenuated (worse) during recall due to sensemaking $[51,71]$. The value creation lens was used to understand the motivation for the participants to engage in this kind of activity as well as the potential empowerment gained through participation, and also to help us to develop our practice (the workshop contents and procedure, participant recruitment) further. This dual level of analysis informs our discussions on critically, empowerment, and value-creation when tackling what might be uncomfortable and personal topics, such as love and romance during and after a pandemic, within the context of India.

\section{FINDINGS FROM THE DESIGN OUTCOMES AND DESIGN PROCESS}

\subsection{Outcomes: Critical and Empowering Alternative Future Scenarios}

The scenarios of the six teams are presented below (S1-S6). In relation to each scenario, for S3-S6, first there is a team-members reflection of how provocative, empowering, and/or shocking the solution is. No team members from S1 and S2 shared their reflections. Then, employing the critical lens, we present the other participants' and organizers' critiques of the scenarios. From the organizers' perspectives, several of the future scenarios built upon existing ideas of virtual reality and virtual worlds. Expectedly, several scenarios shared familiarity with sci-fi movies and books, e.g., about dystopian futures as projected in the movie HER and the book Brave New World. The movie Avatar was also referenced by multiple groups, directly or indirectly, and character avatars in virtual worlds were also mentioned. However, our intention is not to judge or grade the ideas but rather to highlight how within a short workshop, several groups considered critical, provocative, and empowering scenarios only after a short introduction to design fiction. Participant critiques presented below are a mix of self-critique 
(groups analysing their own team's scenario) and critiques of other teams.

Scenario 1: Long distance relationships. Resolving the absence of physical sensations in long distance relationships through wearable jackets and gloves that simulate the physicality of hugs and handholding, with another device that releases a loved one's pheromones. However, these solutions have evident pitfalls - possibility of misuse by having the device impersonate an ex. Participant critique: "The idea of using simulation jackets is critical as it claims to 'enhance' existing human relationships through intervention of inanimate objects. . . it can evoke emotions by simulating smell and touch by customising it according to the preference of its wearer/user. The prospect of having a huggable jacket is foregrounded as the sole solution to the absence in physical intimacy in long distance relationships." Organizer critique: Incorporating both touch and smell in commonly worn clothes, like a jacket and gloves, is an interesting idea - one that defines the essence of human-human intimacy and emotion. The addition of pheromones to a huggable jacket inspires a proposal for change and caution against its misuse (to impersonate an ex, assumingly for creating unpleasant experiences), makes one reflect on our current interpersonal relationships - do we want to be reminded of the smell of an ex?

Scenario 2: Personal and professional worlds separated. Personal virtual worlds where people connect to a virtual world through their minds using wearable devices, as opposed to their professional worlds which remain real (physical). Can these two worlds co-exist simultaneously? Participant critique: "This design provides a new and interesting perspective in the domain of sociocultural environments in future. The users can perceive distinguished worlds based on their choice of interest. It's thus, a provocative act of an alternative way of living while interacting with the wearable. With this design, the users can be made aware of the two environments, while enjoying the relevance of both." Organizer critique: This scenario presents an uncomfortable sanitized existence, one where our professional worlds, usually devoid of physical intimacy and sometimes also of strong emotional connections, are real and physical, while intimacy is relegated to the virtual. With virtual, you can play it as you like. It provokes us to reflect on our current situation in this pandemic - why would one want to touch a person, when they can touch (and sanitize) their devices?

Scenario 3: A dating application. With both human and robot profiles and where finding affection in an unreal being is possible. Dating consists of co-creating virtual and intellectual spaces together with a human or a robot. Team member reflection: "This artificial being is an embodiment of how one would wish for their future partner to look, feel, think and behave [...]. Designing an 'ideal albeit unreal' soulmate versus finding a 'real flawed human' is a preposterous idea. However, the aspect of co-creating a virtual space for both of them to co-exist together is an empowering one." Participant critique: "This [...] goes against the philosophy that love and relationships are formed on mutual respect and understanding of one another, and not on an individual's perception of how his partner should look, think, feel and behave. [...] The self-centeredness, and inflexibility that this App calls for in 'designing your mate' over actually making the effort to 'find them' is an alarming notion of how people's perceptions towards concepts like love and friendships are becoming more transactional and automated." Organizer critique: Considering AI or artificial companions as common as human ones is a dystopian future in many of our minds. That raises a question of how can we know who is an android; do we need to do a Voight-Kampff analysis to test their humanity, like in the movie Blade Runner? It's a very lonely scene that a machine is one's only friend. However, this scenario, while uncomfortable, also makes us question - will it actually be that bad, considering that so many people are alone and without emotional or physical support especially during the pandemic. Does it matter whom we date if our worlds are virtually co-created, our lives a culmination of zeros and ones?

Scenario 4 Virtual interaction reigns our lives. The politics of the pandemic remains intact over decades, resulting in a reconfiguration of all human relationships, increasingly mediated by digital technology. Dating begins online and remains online till the 10th date where the first touch of holding hands is initiated. With weddings held separating and quarantining the new honeymooners, we are all prisoners of our own physical world. Team member reflection: 'The online medium's flourish has immensely aided globalization in recent times. However, that has also led to the decline of tradition, heritage, and personal, genuine touch in relationships. This feeling of discomfort regarding the future in technology allowed me to start thinking from a new perspective. [...] I now wanted to imagine the future in a way that was less superficial and more real. The future of technology should be environmentally sustainable and catering to the needs of the people." Participant critique: "[This scenario] serves as an optimal context for the development of critical design as it reflects upon the perils of substituting all first-hand human contact by technomediated experiences. It also holds promise of aesthetic criticism by making room for aesthetic speculations by means of developing the topic, purpose, functionality, interactivity, form and materiality. 'Honeymoon is spent under quarantine'. This proposition forces a change or perspective in the way we culturally conceive the honeymoon, from being a promise of choice and freedom to one of sacrifice and inevitability." Organizer critique: Would human-to-human touch be a rare commodity in the future, one that requires building layers of trust on the interwebs of our everyday existence before we can even hold hands. Can we live without human touch? What happens when no-one touches us, never? What happens to our nerves - do they shrivel and die? Reflecting on the upside down and inside out experiences during this pandemic, our priorities in the future will be undeniably different.

Scenario 5: All education happens in a virtual world. The classroom of the future, where most friendships are initiated, is virtual, accessible also to those with vision and auditory impairments, and utilizes holographics. We are teleported into classrooms with our avatars in a social virtual world. Team member reflections: "Since all of us are going through COVID pandemic physical education is a challenge. [...] The design [...] gives people with disability a possibility to remove the barriers and limitations they may have during their learning and education. For example, for deaf people with a holographic sign language teacher side by side with an actual teacher, [they] could participate in public school. With this kind of design, we could eliminate the isolation that people with disability may encounter in their society and accept them as part of society. This kind of empowering design could only be reached with critical design." Participant critiques: "This also raises the question of [..] what age group would it be appropriate for? Would teleportation be 
Table 2: Value creation as thematically analysed from the feedback forms

\begin{tabular}{|c|c|}
\hline Focus of value creation & Experienced value \\
\hline Workshop itself & $\begin{array}{l}\text { Interesting workshop method; An idea of how to conduct a workshop; Interesting topic for the team } \\
\text { work; Reducing pedagogic anxiety; Having fun }\end{array}$ \\
\hline New knowledge & New knowledge about critical design \\
\hline Design & New insight into the design field \\
\hline Teamwork & $\begin{array}{l}\text { Working in a team with people with different backgrounds; Working with new people who have } \\
\text { new ideas; The team activity itself }\end{array}$ \\
\hline New possibilities & Possibility to write a paper with organizers; Possibilities for new collaborations and opportunities \\
\hline New inspiration & $\begin{array}{l}\text { Inspiring on a personal level through insight of how the world could change; New inspiration and } \\
\text { ideas to a specific research topic; Re-imagining privacy, work from home, online education, } \\
\text { misinformation }\end{array}$ \\
\hline Professional development & $\begin{array}{l}\text { Thinking beyond the ordinary scopes helps imagination and that in turn helps to get new ideas for } \\
\text { work; New thoughts to continue research during the pandemic }\end{array}$ \\
\hline
\end{tabular}

considered as an appropriate mode of commute for kindergarteners? In addition, with respect to the prospect of creating digital avatars of yourself and projecting it into a shared space to create the feeling of a 'physical classroom', what could be the limitations? Would users in their formative years benefit from this kind of virtual interaction?" Organizer critique: At first, this scenario feels surprisingly comfortable, where sci-fi and familiarity with technology development and experiments as well as a COVID-19 induced pressure for online teaching allow us to be more accepting of change. When bringing children into the picture, discomfort arises, however. What happens to the physical body of a toddler when they go to a virtual kindergarten? This scenario underlines the significance of context in interpreting the criticality of design.

Scenario 6: Online friendship Friendships are now all online and virtual with haptic devices simulating physical touch. Team member reflections: "(We) decided to tackle the issue of friendship in the future. We observed that physical presence and interaction plays a very important role in human relationships. A pat on the shoulder or a hug is considered a way to express emotion while interacting with fellow mates. We decided to create a mixed reality solution with haptics to include a way to feel the physical touch of a person. The major drawback was that even though the system provides a way to keep in touch with old friends, it doesn't provide a solution for making new friendships.” Participant critique: "[...] physical presence and interaction plays a very important role in human relationships. [... ] COVID-19 pandemic has made us realise that futuristic problems/scenarios are not far and can occur at any time." Organizer critique: This scenario raises more questions than it answers: what if in the future we only know people as their avatars? How would we make new friends? Could we go to an avatar party using virtual glasses? Could there be loud music and dancing and a big rush? Would it feel the same when we dance with somebody? While going virtual in-part is possible already; being only virtual is discomforting and disconcerting.

\subsection{Process, Short-term: Immediate Experiences and Perceived Value}

Thirteen participants responded to the anonymous feedback survey. Participant motivations included interest in design fiction (or critical design), a drive to explore the topic with the HCI community, and a passion and curiosity towards learning new concepts and tools. This is not surprising, as the workshop was a part of ACM SIGCHI Mumbai Chapter Meet, and it was advertised within the Indian HCI community and we had over 50 registration, with 34 participants at the start and 29 till the end of the actual workshop. Considering the value experienced by the participants (see [Table 2]), they mentioned enjoying the workshop and its topic, the team activity and ideation phase. One participant mentioned that it was an opportunity to meet new people and explore new ideas. The team activity was appreciated so much that participants mentioned disliking the short amount of time (30 minutes) allocated to it, and the short duration of the workshop in general ( 90 minutes). Further, one participant mentioned a lack of feedback on their scenarios as something they disliked.

Many of the participants found the workshop inspiring, at a personal level "my time is now being spent on trying to read and understand more of the concepts surrounding this branch of design", and also professional level, "my area of research is Public Transport and this inspired me to brainstorm about possibilities in public travel, in both the near and distant futures!" One participant mentioned not being inspired professionally or personally, while another mentioned part professional growth, "being a complete novice in this field, the scope and the possibility of applying this to my domain excited, while also left me trying to understand how to go about it". Improvements for the workshop mainly consisted of suggestions to make it longer, more streamlined, modular, and focused, with a "written report on holding a workshop and summarizing comments... provided to the participants". Only one participant commented on the team formation, but it is unclear if this was due to the uncomfortable nature of the topic of romance, or something else. Overall, the workshop was well received by the participants, and from the organizers' perspective, while teething pains were expected (being a first of its kind), a valuable and empowering learning experience for all those involved. 
Table 3: Value creation as thematically analysed from the feedback forms

\begin{tabular}{ll}
\hline Focus of value creation & \multicolumn{1}{c}{ Experienced value } \\
\hline \hline Workshop as an experience & $\begin{array}{l}\text { The workshop was an exciting experience; The workshop encouraged free thinking; The workshop } \\
\text { topics created an inception towards barrier-free thinking, beyond normal limitations of everyday } \\
\text { work; Interesting discussions on technology; Working with the topics as a team was empowering; } \\
\text { Feeling of empowerment as a researcher through new angles of thought }\end{array}$ \\
& Learning about critical design \\
Learning & Excitement over designing for undesired future \\
Future & Interesting designs that provoked thoughts on possible futures \\
& Making the technology presented in science fiction feel more possible; New thoughts about future of \\
technology; Taking a look to the future without constraints of what is currently possible; Giving new & directions for thoughts about future technology, by showing what kind of future is not appealing \\
& Opening up the possibilities of human imagination; Opening new horizons for thinking and design; \\
& Changing the perspective of what and how we design away from functionality and problem-solving; \\
& Realization of how something uncomfortable or shocking can manifest in a useful design if you are \\
able to channel your thoughts suitably; Participants engaged in philosophical ponderings on future, & future of technology, what is design and how we design?
\end{tabular}

\subsection{Process, Long-term: Critical, Empowering, and Value-creating}

Asking participants to reflect on their workshop experiences and designs, and critically analysing their own and other designs two months later allows us to further consider long term value gains from participation, and whether those gains are empowering. We focus our criticality, empowerment, and value-creation lenses specifically on the topic of friendships and romance, and the shock and discomfort produced, and how participants reflected upon and took forward that shock and discomfort. Compared to the feedback received immediately after the workshop, the reflections two months later were deeper and more enthusiastic, probably due to sensemaking and more focused working with the potentials of critical design. Naturally, people who sent us their reflections were also the most willing ones to reflect on their experience, which can also explain the enthusiasm.

Many participants, unsurprisingly, were uncomfortable discussing romance with strangers in a workshop, stating "a reluctance amongst my team to discuss the future of romance. Romance and romantic intimacy are very personal and subjective". Several participants attributed this reluctance to "Indian culture is still very conservative when it comes to discussing romance and physical intimacy in detail" and to a "high number of online dating/romance scandals uncovered every day, especially in India". They further stated that, as a researcher there "might be a prejudice that the futuristic solutions might get used for these unethical frauds." One participant mentioned "romance was an awkward subject to talk about in a team with huge age differences and unfamiliarity", yet for another it "was a little bit shocking, [but] not annoying at all." Several participants reflected further on how they channelled their discomfort and to start to consider more provocative alternative future scenarios, "it created a range of mild to acute discomfort, caused by quick flashes of reflections made about the present characteristics of online relationships and some imagined future possibilities." And relating it to the pandemic situation, "anguish was perhaps the underlying negative emotion, triggered by the thought of being unable to ever again touch another human being". When looking closer at the kind of value experienced by participants ([Table 3]), we see that in addition to enjoying the workshop itself and obtaining a preliminary understanding of what is meant by critical design, there was also much appreciation of, and awe towards design fiction as a tool that enables HCI researchers to break out of the box; to shock and be shocked, as one of the participants described: "as an HCI researcher I must say that our thoughts and futuristic designs generally derived from available technological advancement, contemporary research, 'plausible' ideas targeted for near future. On the contrary, the workshop encouraged the participants to think beyond existing ideas and look far into the future (after 100 years). It was an exciting experience that opened a new avenue of thoughts".

As for criticality, we argue that the workshop managed, to an extent, to integrate provocative, shocking, uncomfortable, disturbing, absurd, and preposterous aspects both in terms of the design process and outcome. In their designs, participants managed to reject how things currently are as the only option and proposed designs that embody alternative values [[27]: 58]. Their proposals aroused reflection, opened up taken for granted assumptions, and/or provoked the audience, in some respects. The design process was also seen as including provocative, shocking, uncomfortable aspects, encouraging out of the box thinking, creativity and reflection. The participants also considered the experience empowering. Interestingly, we found evidence of the participants considering empowerment from two different perspectives - even if we did not intentionally plan to introduce this diversity to them. We think for some of the participants, empowerment appeared as a motivational construct, relating to value creation through their own development and professional growth. They found design fiction an exciting, interesting, valuable new method in their method repertoire, empowering them as designers to tackle uneasy situations and topics, and uncertain futures - the workshop nurturing self-efficacy, and/or meaningfulness [39, 65]. Empowerment here connects strongly with learning and competence development (see e.g. [45]) which 
was an obvious aim of the workshop as well. However, we also noted alternative interpretations of empowerment, those relating to social responsibility and empowerment of someone else. Some participants considered, for example, people with disabilities and their futures in their designs (see e.g. [39, 42]). This view on empowerment is definitely a valid one as well. We find it intriguing that our participants approached this topic from these different angles. We discuss their implications for design practice and education in the following section.

\section{DISCUSSION}

The Covid-19 pandemic has made us question the new normal of our interpersonal relationships - from those at work to our personal and intimate experiences. With various states of lockdowns and social distancing across the world, the current situation provides an abundance of opportunities for us all to reconsider technologies around social presence - for better communication, companionship, and collaboration. From transporting our lives wholly to virtual spaces, to recreating human intimacy through wearable and haptic technologies, and varied types of sensory based multimodal interactions seamlessly blending the real and the virtual. With this in mind, we conducted a design fiction workshop, exploring the future of friendships and romance in a post-pandemic world, which we can only make guesses of what it will be like. Together with the participants, we probed and pondered intimacy and how it could be re-conceptualised, along with the technologies that could enable, mediate, and in some cases replace social connections with other human and non-human beings.

\subsection{Can Design Fiction Enable Participants to Critically Explore Sensitive Topics?}

We were interested in the potential of design fiction to arouse criticality and to empower participants to explore the topic of intimacy. We conducted a workshop as a part of an Indian ACM SIGCHI chapter meet, with predominantly Indian participants. We acknowledged that in the context of India, there is so far very limited research on the topic while also some evidence that exploring the topic of intimacy might be challenging. We examined criticality and empowerment both from the viewpoint of the design outcomes and design process. As for criticality, we considered the provocative, shocking, uncomfortable, disturbing, absurd, preposterous nature of design outcomes and the design process. The design outcomes indeed included some provocative aspects that forced the participants as well as the organizers to reconsider their taken for granted assumptions. Some of the design outcomes can also be considered empowering, in motivational and/or in relational sense; the design outcomes allowing people to have increased power to shape their lives and intimacy within, providing them novel ways and flexibility in terms of experiencing, engaging in and shaping their interactions, relationships, romantic encounters. Given the flourishing interest in designing technologies aimed at mediating (and creating) a feeling of relatedness in romantic and other close relationships [34], the topic and timing were opportune. Studies revolving around using technology to help in discovering, maintaining and fostering relationships have been conducted - be it in terms of proposing strategies [34] or developing methods and tools to support them
$[10,28,59]$. From studying user behavior while entering personal data into dating profiles [28], to exploring user relationships with artefacts to stimulate feelings of love and connectedness [59], studies have focused on exploring the various stages of interaction users have with technology for well-being. Understanding love as an action brings up the possibility to make use of existent or future technologies may help to improve love [59]. Themes of connectedness, intimacy, love, belonging, closeness, and togetherness have been subsumed under the broad label of relatedness [34]. However, the possibility of finding and maintaining relationships in a postCovid era require, not necessarily always new devices but, new contexts and possibilities of use. We maintain that HCI research should now take the lead in envisioning our radically transformed futures, including the futures of intimacy within. We need to be empowering people to re-imagine those futures and we propose design fiction as a tool for that.

In terms of criticality and empowerment, we provided evidence of our design fiction process being perceived as provocative by the participants, compelling them to address uncomfortable topics in uneasy situations. Empowerment appeared in the workshop reflections in several senses: in relation to the design process for designers through competence building in alternative, speculative, critical approaches and methods. Then again, it appeared in the design outcomes as an aim to serve those currently marginalized or oppressed, for instance, students with vision and auditory impairments. We argue that design fiction should be embraced for its potential each of these senses. Novel in our study is the context and the nature of the design process in that we inquired using design fiction with non-experts. in the socio-cultural context of India. Non-experts are not the usual user group of design fiction in $\mathrm{HCI}$ or design research, even if we managed to find some related research on design fiction for all. Design fiction has been used with children and university students in educational settings through various topics, and in design education generally. The existing literature, however, is lacking reflective discussions on the benefits and challenges involved in non-experts' initial encounters with design fiction. Critics may say the design fiction outcomes generated in our workshop were not that shocking, provocative, or wild. However, considering our participant group and context, we maintain we generated fascinating results in terms of critical and empowering design ideas and design experiences. We wish to highlight that both the literature (see e.g. [[41]) and our participants pointed out that in this cultural context the topic is challenging to address, particularly with strangers. For non-experts, engaging in such a reflective, uncomfortable and critical endeavour is not a straightforward or easy to task to accomplish. For these reasons we maintain that our results show we indeed have managed to push the boundaries, to encourage and to challenge our participants to collaboratively scrutinize and explore such an uncomfortable, uneasy topic - and even within such a limited timeframe.

Based upon our study, we recommend experiments entailing design fiction with critical and empowering elements to tackle a variety of uncomfortable, uneasy topics, also with non-expert participants. Such design fiction enables the designer to provoke as well as to be provoked: inviting designers to explore and envision controversial or uncomfortable topics empowers them to approach 
the world critically, to question how things currently are, to consider alternative presents and futures, to reveal taken for granted assumptions (see e.g. $[5,6,10,26,40])$. We see that experiencing a provocative design fiction process contributes to the professional growth of a designer, which is what the workshop participants also reported to us, i.e., the experience was enabling and encouraging, and it empowered (see e.g. [39, 45]) them to think a bit differently about their own work, about different design topics, about future technologies, and about the world more generally. In the new normal initiated by the pandemic, the type of skills and competencies offered through engaging in design fiction may become ever more crucial, empowering the designer to reimagine as well as to work towards alternative, and maybe even better futures. We also wish to highlight another interpretation of empowerment evident in the workshop, concerning the design outcome: empowerment of those currently oppressed or marginalized (see e.g. [39, 45]). Even if the design outcomes were not particularly strong in combating the oppressors or critically scrutinizing the current state of affairs, we see valuable developments in this direction. We maintain that reflection on the ethical and value-laden nature of design is an essential part of design education and we happily report on the potential of design fiction in arousing reflection on these matters. Arousing future designers' as well as the general public's awareness of and criticism towards the oppressing conditions of the status quo. In addition to their interest to work for making the world a better place for those currently suffering can be a significant endeavor.

\subsection{What kind of Value Does (Online) Design Fiction Bring to the Participants?}

Employing a value-creation lens to the design outcomes and process of the workshop, two aspects were observed. First, value was identified through utilizing design fiction, considering the topic of interpersonal relationships, and focusing on the future, rather than the present. Then, within the context of the pandemic, participation in workshops (or other hands-on seminars etc) is one of the few mechanisms available to us for meeting and collaborating with people (friends, acquaintances, and strangers) with similar interests. With limited opportunities for serendipitous physical encounters with people. e.g., at a university or a conference, workshops can enable these kinds of interactions in a virtual space. Next, we unpack these two aspects.

Considering this workshop, its focus on interpersonal relationships, something that affects us all and our experiences of which have certainly changed since March 2020, allowed participants (with varying levels of expertise in design fiction and design research in general) to contribute to the discussions, and to the design of scenarios. It also gave them an opportunity to pause and reflect upon their own personal and professional relationships, values and priorities, and how these may have changed during the pandemic. The task to consider not the present, but the future, also created an opportunity for participants to re-evaluate, during and after the workshop, their own priorities and values towards their personal and professional relationships. Learning, and unlearning, in design and HCI is a continuous process, that can be supported by such workshops. For instance, while social virtual reality has been on the fringes of research for several years, many participants considered this as a mainstream solution in building interpersonal relationships in the near future. Design fiction helped us to take a leap into the future, not just in our minds and ideas, but as viable alternatives and solutions.

Breaking physical (and economical) barriers, online workshops and seminars enable people from across the world to meet and collaborate, in many instances, creating new avenues and directions for research that would not have been possible previously (e.g., if the workshop was held physically). How? Moving online, through video calls, more detailed emails, or sharing and collaborating on documents, creates a transparency in sharing of ideas, collaborations, and processes. Further still, given a blank online canvas to ideate on (e.g. Google slides or Miro), democratizes participation by allowing multiple ways to contribute - via text, images, voice etc, and multiple contributions simultaneously, thus, sharing the spotlight (with those who would otherwise be quiet in a physical group discussion). Moreover, online collaboration can be anonymous too, reducing the fear of being judged or expressing controversial ideas, and debating and tacking important socio-technical or socio-cultural issues through discussions with a curated, through event advertisements or signup forms, yet diverse group of individuals. We are not advocating design fiction workshops to move entirely online, but we wish to point out that online engagement may ease collaborative exploration of sensitive or uncomfortable topics. In online environment with strangers, discussing and envisioning intimate topics might even be easier to do than face to face with familiar people. However, this is a topic that needs to be explored further in future studies.

As we all adjust to our forever changed lives and work during this pandemic, there are risks of burnout and demotivation. Only time will tell if workshops and seminars can inspire us, bring in new ideas and perspectives, and provide mechanisms to improve mental health (by for instance, finding communities of like-minded people, or people going through similar challenges) Or are we better off in the future with hybrid ways of working - democratizing online spaces and communities, to achieve inclusion and diversity of thoughts, ideas, approaches, and groups ... as we dream of in HCI.

\subsection{Limitations of the Work}

There are limitations to this work, such as the short nature of workshops in general, the small number of participant feedback from the surveys and reflections, and the limited workshop time; we still argue in favor of design fiction as a process and also for its outcomes. We also highlight the value created through sustained interactions and reflections (e.g. months after the workshop). Regarding engagement with participants after the workshop, in our case to obtain feedback, other forms of incentives are required in addition to collaborative paper writing and data analysis. However, living through the pandemic for over a year, several people are experiencing Zoom fatigue. The online nature of workshops, while potentially opening doors to those who might not have otherwise participated, also brings its own limitations. For instance, the visual nature of video conferencing might have had an influence on how the participants approached the topic - considering more visual and virtual fictions over multisensory ones; although groups did 
consider intimacy and touch, in addition to companionship and conversation. The intimate nature of the topic being discussed with strangers online without the blanket of anonymity, added another level of discomfort to the workshop experience. But then again, our goal to provoke and be provocative, to empower and be empowering, to critique and design critically, was met. Lastly, while we focused on the Indian context, where arranged marriages and kidnapping of spouses are existing realities, however, participants did not consider such wild scenarios, possibly due to the professional nature of the workshop.

\subsection{Future Work}

We conducted another similar workshop in India in Dec 2020 as a part of the IndiaHCI conference, where a different set of participants designed similar design fiction scenarios. For 2021, we are planning for another workshop on topic, this time with an international audience, as a part of the INTERACT 2021 conference $^{1}$. This workshop is open to all who express an interest, including previous workshop participants. As the absurdities of our reality, of love and loss, provoke, shock, and then seemingly become normalized, we hope the workshops will help participants reconsider and reimage the future we are heading towards, to make provocative and shocking changes to the new normal, unearthing the current status quo, and empowering us all.

\section{CONCLUSION}

The forced reboot of our lives due to the COVID-19 pandemic, has us question the current role of technology in our lives, and open up discussions and new opportunities to reimagine alternative futures for our interpersonal relationships. To explore this further, we conducted an online design fiction workshop with HCI professionals and academics, with varying experiences and interests. Design fiction is seen as a tool to design future technologies and is described as a way to envision new technologies while understanding the narratives of the current context and exploring how these technologies can be positioned within a new context. In the context of our workshop, design fiction enabled us, experts and non-experts in design research alike, to consider alternative futures and the use of technology for a culturally sensitive and relatively unexplored topic of romance and technology in India. Workshop participants worked in small teams considering diverse scenarios and different aspects, design solutions, and challenges within those scenarios. Several of the teams started to question fundamental human desires for touch, intimacy, companionship, and romance, and the effects of the pandemic on these desires. They speculated on a spectrum of futures - some that were bleak and dystopian where humanity never recovers from the cruelty of the pandemic, to futures where human-machine relationships are similar, and possibly preferred, to human-human relationships. To comfortably suggest design fiction as a method or tool for participants with diverse backgrounds where participants are provoked yet provocative, empowered yet critical, and shocked or uncomfortable yet questioning the status quo - the organizers and participants critically analysed the scenarios based upon previous work in this domain. Findings from the

\footnotetext{
${ }^{1}$ All workshops are also advertised here https://interact.oulu.fi/researcherstoolbox
}

analysis, workshop feedback and reflections, indicate that participants produced and discussed critical aspects regarding intimacy, dating, and making friends in the future, and were inspired by design fiction as a tool in their personal and professional repertoire. Employing design fiction encouraged participants to think about alternative futures that question the current status quo and empower them in the future.

\section{ACKNOWLEDGMENTS}

This research is connected to the Make-A-Difference project (MAD) at the INTERACT Research Unit and the GenZ project, a strategic profiling project in human sciences at the University of Oulu. The projects are supported by the Academy of Finland (Grant \#318930 and Grant \#324685) and the University of Oulu.

\section{REFERENCES}

[1] James Auger. "Speculative design: crafting the speculation." Digital Creativity 24, no. 1 (2013): 11-35

[2] Payal Arora and Laura Scheiber. "Slumdog romance: Facebook love and digital privacy at the margins." Media, Culture \& Society 39, no. 3 (2017): 408-422.

[3] Ballard, Stephanie, Karen M. Chappell, and Kristen Kennedy. "Judgment call the game: Using value sensitive design and design fiction to surface ethical concerns related to technology." In Proceedings of the 2019 on Designing Interactive Systems Conference, pp. 421-433. 2019.

[4] Jeffery Bardzell, Shaowen Bardzell, and Erik Stolterman. "Reading critical designs: supporting reasoned interpretations of critical design." In Proceedings of the SIGCHI Conference on Human Factors in Computing Systems, pp. 1951-1960. 2014. ACM, NY.

[5] Shaowen Bardzell, Jeffrey Bardzell, Jodi Forlizzi, John Zimmerman, and John Antanitis. "Critical design and critical theory: the challenge of designing for provocation." In Proceedings of the Designing Interactive Systems Conference, pp. 288-297. 2012. ACM, NY.

[6] Shaowen Bardzell. "Utopias of participation: design, criticality, and emancipation." In Proceedings of the 13th Participatory Design Conference: Short Papers, Industry Cases, Workshop Descriptions, Doctoral Consortium papers, and Keynote abstracts-Volume 2, pp. 189-190. 2014.

[7] Bardzell, Jeffrey, Shaowen Bardzell, and Lone Koefoed Hansen. "Immodest proposals: Research through design and knowledge." In Proceedings of the 33rd Annual ACM Conference on Human Factors in Computing Systems, pp. 2093-2102. 2015.

[8] Karl Baumann, Ben Caldwell, François Bar, and Benjamin Stokes. "Participatory design fiction: community storytelling for speculative urban technologies." In Extended Abstracts of the $2018 \mathrm{CHI}$ Conference on Human Factors in Computing Systems, pp. 1-1. 2018. ACM, NY.

[9] Mark Blythe. "Research through design fiction: narrative in real and imaginary abstracts." In Proceedings of the SIGCHI conference on human factors in computing systems, pp. 703-712. 2014.ACM, NY.

[10] Blythe, M., Andersen, K., Clarke, R., \& Wright, P. (2016, May). Anti-solutionist strategies: Seriously silly design fiction. In Proceedings of the $2016 \mathrm{CHI}$ Conference on Human Factors in Computing Systems (pp. 4968-4978).

[11] Mar Blythe, Kristina Andersen, Rachel Clarke, and Peter Wright. "Anti-solutionist strategies: Seriously silly design fiction." In Proceedings of the $2016 \mathrm{CHI}$ Conference on Human Factors in Computing Systems, pp. 4968-4978. 2016. ACM, NY.

[12] Barry Brown, Julian Bleecker, Marco D’adamo, Pedro Ferreira, Joakim Formo, Mareike Glöss, Maria Holm et al. "The IKEA Catalogue: Design fiction in academic and industrial collaborations." In Proceedings of the 19th International Conference on Supporting Group Work, pp. 335-344. 2016. ACM, NY.

[13] Manuela Celi and Formia Elena. "Advanced Design Practices for Sharing Futures: A Focus on Design Fiction." In THE VALUE OF DESIGN RESEARCH 11th International European Academy of Design Conference, April 22-24th 2015, pp. 1-13. FRA, 2015.

[14] Cocci, Andrea, Daniel Giunti, Camilla Tonioni, Giovanni Cacciamani, Riccardo Tellini, Gaia Polloni, Gianmartin Cito et al. "Love at the time of the Covid-19 pandemic: preliminary results of an online survey conducted during the quarantine in Italy." International journal of impotence research 32, no. 5 (2020): 556-557.

[15] Vinton G. Cerf. 2020. Implications of the COVID-19 pandemic. Commun. ACM 63, 6 (June 2020), 7. DOI:https://doi.org/10.1145/3397262

[16] Kabita Chakraborty. "Virtual mate-seeking in the urban slums of Kolkata, India." South Asian Popular Culture 10, no. 2 (2012): 197-216.

[17] Das Chakraborty. Why Indians Are Flocking To Dating Apps To 'Beat' The Lockdown. Huffington Post, India. 24 May, 2020. Retrieved September 03, 2020 
from https://www.huffingtonpost.in/entry/indians-dating-app-lockdown_in 5ec9796dc5b607a94dedb946.

[18] Sanaya Chandar. A Psychologist explains why young Indians are anxious about dating. 2020. Retrieved from Quartz India, February, 2020 (viewed on 13/09/2020) https://qz.com/india/1799927/a-psychologist-on-why-youngindians-are-anxious-about-dating/

[19] Jay A. Conger and Rabindra N. Kanungo. "The empowerment process: Integrating theory and practice." Academy of management review 13, no. 3 (1988): 471-482.

[20] Paul Coulton, Joseph Galen Lindley, Miriam Sturdee, and Michael Stead. 2017 'Design Fiction as World Building'. In Proceedings of the 3rd Biennial Research Through Design Conference, 11. pp. 163- 179. DOI: 10.6084/m9.figshare.4746964. 2017.

[21] Paul Coulton. "Reflections on teaching design fiction as world-building." Speculative and Critical Design in Education: Practice and Perspectives (2020).

[22] Vishnupriya Das. "Dating Applications, Intimacy, and Cosmopolitan Desire in India." Global Digital Cultures: Perspectives from South Asia (2019): 125.

[23] Carl DiSalvo and Jonathan Lukens. "Nonanthropocentrism and the nonhuman in design: possibilities for designing new forms of engagement with and through technology." From social butterfly to engaged citizen: urban informatics, social media, ubiquitous computing, and mobile technology to support citizen engagement 421 (2011).

[24] Dindler, C., \& Iversen, O. S. (2007). Fictional inquiry-design collaboration in a shared narrative space. CoDesign, 3(4), 213-234.

[25] Duggan, J. R., Lindley, J., \& McNicol, S. (2017). Near Future School: World building beyond a neoliberal present with participatory design fictions. Futures, 94, 15-23.

[26] Dunne, A. and Raby, F. (2007). Critical Design FAQ. Retrieved April 26th, 2021. http://www.dunneandraby.co.uk/content/bydandr/13/0

[27] Dunne, Anthony, and Fiona Raby. Speculative everything: design, fiction, and social dreaming. MIT press, 2013

[28] Elsden, C., Nissen, B., Garbett, A., Chatting, D., Kirk, D., \& Vines, J. (2016, May) Metadating: exploring the romance and future of personal data. In Proceedings of the 2016 CHI Conference on Human Factors in Computing Systems (pp. 685-698)

[29] Sidney Fels. 2000. Intimacy and embodiment: implications for art and technology. In Proceedings of the 2000 ACM workshops on Multimedia (MULTIMEDIA '00). ACM, NY. DOI:https://doi.org/10.1145/357744.357749

[30] Laura Forlano and Anijo Mathew. "From design fiction to design friction: Speculative and participatory design of values-embedded urban technology." Journal of Urban Technology 21, no. 4 (2014): 7-24.

[31] Zhiyong Fu and Lin Zhu. "Envisioning the Future Scenario Through Design Fiction Generating Toolkits." In International Conference on Human-Computer Interaction, pp. 46-59. Springer, Cham, 2020

[32] Cally Gatehouse. 2020. Coronavirus and the carnivalesque: what speculative methods can tell us about Covid-19. ACM Interactions 27, 4 (July - August 2020), 34-36. DOI:https://doi.org/10.1145/3403888

[33] Hauser, Sabrina, Audrey Desjardins, and Ron Wakkary. "Sfuture: envisioning a sustainable university campus in 2065." In Proceedings of the 2014 companion publication on Designing interactive systems, pp. 29-32. 2014.

[34] Hassenzahl, M., Heidecker, S., Eckoldt, K., Diefenbach, S., \& Hillmann, U. (2012). All you need is love: Current strategies of mediating intimate relationships through technology. ACM Transactions on Computer-Human Interaction (TOCHI), 19(4), 1-19.

[35] Gopinaath Kannabiran, Jeffrey Bardzell, and Shaowen Bardzell. 2011. How HCI talks about sexuality: discursive strategies, blind spots, and opportunities for future research. In Proceedings of the SIGCHI Conference on Human Factors in Computing Systems (CHI '11). ACM, NY, USA, 695-704. DOI:https://doi.org/10. 1145/1978942.1979043

[36] Christian Grönroos. 2011. "Value Co-Creation in Service Logic: A Critical Analysis," Marketing Theory (11:3), pp. 279-301.

[37] Alison Hardy. "Using design fiction to teach new and emerging technologies in England." Technology and Engineering Teacher 78, no. 4 (2018): 16-20.

[38] Kristina Heinonen, Tore Strandvikm and Päivi Voima (2013). Customer dominant value formation in service. European business review (25):2, 104-123.

[39] Juhani Iivari. "A Critical Look at Theories in Design Science Research." Journal of the Association for Information Systems 21, no. 3 (2020): 10.

[40] Netta Iivari and Kari Kuutti. "Critical design research and information technology: Searching for empowering design." In Proceedings of the 2017 Conference on Designing Interactive Systems, pp. 983-993. 2017. ACM, NY.

[41] Smitha Jha. "Love on the Run: An Analysis of User Behaviour in Online Dating." (2016) International Journal of Advanced Research in Computer Science and Software Engineering. Volume 6, Issue 3, March 2016 ISSN: 2277 128X.

[42] Louise B. Jennings Deborah M. Parra-Medina, Deanne K. Hilfinger-Messias, and Kerry McLoughlin. "Toward a critical social theory of youth empowerment." Journal of Community Practice 14, no. 1-2 (2006): 31-55.

[43] Marianne Kinnula, Netta Iivari, Minna. Isomursu, and S. Laari-Salmela. 2018 "'Worksome but Rewarding' -Stakeholder Perceptions on Value in Collaborative Design Work," Computer Supported Cooperative Work: CSCW: An International Journal (27:3-6), pp. 463-494.
[44] Marianne Kinnula, Netta Iivari, Minna Isomursu, and Henrietta Kinnula. "Socializers, achievers or both? Value-based roles of children in technology design projects." International Journal of Child-Computer Interaction 17 (2018): 39-49.

[45] Marianne Kinnula, Netta Iivari, Tonja Molin-Juustila, Eino Keskitalo, Topi Leinonen, Eetu Mansikkamäki, Toni Käkelä, and Martti Similä. "Cooperation, Combat, or Competence Building-What Do We Mean When We Are 'Empowering Children' in and through Digital Technology Design?." In ICIS. 2017.

[46] Sandjar Kozubaev, Chris Elsden, Noura Howell, Marie Louise Juul Søndergaard, Nick Merrill, Britta Schulte, and Richmond Y. Wong. "Expanding Modes of Reflection in Design Futuring." In Proceedings of the 2020 CHI Conference on Human Factors in Computing Systems, pp. 1-15. 2020. ACM, NY.

[47] Eva Knutz, Tau Ulv Lenskjold, and Thomas Markussen. "Fiction as a resource in participatory design." In Proceedings of DRS 2016 International Conference: Future-Focused Thinking, pp. 1830-1844. Design Research Society, 2016.

[48] Sari Kujala and Kaisa Väänänen-Vainio-Mattila. "Value of information systems and products: Understanding the users' perspective and values." Journal of Information Technology Theory and Application (JITTA) 9, no. 4 (2009): 4.

[49] Effie Lai-Chong Law, Virpi Roto, Marc Hassenzahl, Arnold P.O.S. Vermeeren, and Joke Kort (2009).Understanding, scoping and defining user experience: a survey approach. In Proceedings of the SIGCHI Conference on Human Factors in Computing Systems, ACM, NY. 2009. 719-728.

[50] Sus Lyckvi, Virpi Roto, Elizabeth Buie, and Yiying Wu. "The role of design fiction in participatory design processes." In Proceedings of the 10th Nordic Conference on Human-Computer Interaction, pp. 976-979. 2018.

[51] Sally Maitli and Marlys Christianson. "Sensemaking in organizations: Taking stock and moving forward." Academy of Management Annals 8:1. 2014. 57-125.

[52] Thomas Markussen and Eva Knutz. "The poetics of design fiction." In Proceedings of the 6th International Conference on Designing Pleasurable Products and Interfaces, pp. 231-240. 2013.

[53] Deborah Maxwell, Toby Pillatt, Liz Edwards, and Rachel Newman. "Applying Design Fiction in Primary Schools to Explore Environmental Challenges." The Design Journal 22, no. sup1 (2019): 1481-1497.

[54] Michael Muller and O. Vera Liao. "Exploring AI Ethics and Values through Participatory Design Fictions." Human Computer Interaction Consortium (2017).

[55] Michael Muller, Jeffrey Bardzell, EunJeong Cheon, Norman Makoto Su, Eric PS Baumer, Casey Fiesler, Ann Light, and Mark Blythe. "Understanding the Past, Present, and Future of Design Fictions." In Extended Abstracts of the $2020 \mathrm{CHI}$ Conference on Human Factors in Computing Systems, pp. 1-8. 2020.

[56] Nägele, L. V., Ryöppy, M., \& Wilde, D. (2018, September). PDFi: participatory design fiction with vulnerable users. In Proceedings of the 10th Nordic Conference on Human-Computer Interaction (pp. 819-831).

[57] Nimmy Rangaswamy and Payal Arora. "The mobile internet in the wild and every day: Digital leisure in the slums of urban India." International Journal of Cultural Studies 19, no. 6 (2016): 611-626.

[58] Prost, S., Mattheiss, E., \& Tscheligi, M. (2015, February). From awareness to empowerment: Using design fiction to explore paths towards a sustainable energy future. In Proceedings of the 18th ACM Conference on Computer Supported Cooperative Work \& Social Computing (pp. 1649-1658).

[59] Pujol, R. S., \& Umemuro, H. (2009). Productive love: A new approach for designing affective technology. In CHI'09 Extended Abstracts on Human Factors in Computing Systems (pp. 2469-2478).

[60] Gopalan Ravindran. "Mobile Phone Intimacies and Moral Panics in India." Plaridel 7, no. 2 (2010).

[61] Sekhose, Marcia. 2020 Bumble, a dating app, has 4 million users in India. Article retrieved on April 26th 2021 from https://tech.hindustantimes.com/tech/news/ bumble-hits-4-million-users-in-india-women-continue-to-make-the-firstmove-71596094558381.html

[62] Bruce Sterling. "Shaping things." (2005)

[63] Søndergaard, M. L. J., \& Hansen, L. K. (2018, June). Intimate futures: Staying with the trouble of digital personal assistants through design fiction. In Proceedings of the 2018 Designing Interactive Systems Conference (pp. 869-880).

[64] Theresa Tanenbaum. (2014). Design fictional interactions: why HCI should care about stories. ACM Interactions. 21. 22-23. 10.1145/2648414.,

[65] Kenneth W. Thomas and Betty A. Velthouse. "Cognitive elements of empowerment: An "interpretive" model of intrinsic task motivation." Academy of management review 15, no. 4 (1990): 666-681.

[66] Stephen L. Vargo and Robert F. Lusch. "Service-dominant logic: continuing the evolution." Journal of the Academy of marketing Science 36, no. 1 (2008): 1-10.

[67] Frank Vetere, Martin R. Gibbs, Jesper Kjeldskov, Steve Howard, Florian 'Floyd' Mueller, Sonja Pedell, Karen Mecoles, and Marcus Bunyan. 2005. Mediating intimacy: designing technologies to support strong-tie relationships. In Proceedings of the SIGCHI Conference on Human Factors.

[68] Joseph Voros. 2017, 'Big History and anticipation: Using Big History as a framework for global foresight', Handbook of anticipation: Theoretical and applied aspects of the use of future in decision making, Springer International, Cham. doi:10.1007/978-3-319-31737-3 95-1

[69] Wong, R. Y., Van Wyk, E., \& Pierce, J. (2017, June). Real-fictional entanglements: Using science fiction and design fiction to interrogate sensing technologies. In 
Proceedings of the 2017 Conference on Designing Interactive Systems (pp. 567579).

[70] Yiying Wu, Sus Lyckvi, and Virpi Roto. "What is Fair Shipping, Anyway?: Using Design Fiction to Raise Ethical Awareness in an Industrial Context. In Proceedings of the 2019 CHI Conference on Human Factors in Computing Systems, pp. 1-13. 2019.

[71] Karl E. Weick (1995). Sensemaking in organizations. Thousand Oaks, CA: Sage.

[72] Wong, R. Y., Van Wyk, E., \& Pierce, J. (2017, June). Real-fictional entanglements Using science fiction and design fiction to interrogate sensing technologies. In Proceedings of the 2017 Conference on Designing Interactive Systems (pp. 567579).
[73] Emily york, Shannon N. Conley, and Samuel Kodua. "The STS Futures Lab at James Madison University: Integrating Design Fiction, Experimental Pedagogy, and Anticipatory Research into STEM Education and Outreach." CIRCE MAGAZINE: STEAM EDITION (2019): 81.

[74] Emily York, Shannon N. Conley, Anne D. Henriksen, Dorothy Caserta, Noah Etka, Nolan Harrington, Meghan Jennings et al. "Co-imagining the futures of implementation precision medicine using scenario analysis and design fiction." Omics: a journal of integrative biology 23, no. 7 (2019): 340-349.

[75] York, E., \& Conley, S. N. (2020). Creative Anticipatory Ethical Reasoning with Scenario Analysis and Design Fiction. Science and Engineering Ethics, 26(6), 2985-3016. 